\title{
UNAMUNO Y BOLÍVAR: INVENCIÓN DE UN PASADO
}

\author{
FRANCISCO VILLENA GARRIDO
}

\section{INTRODUCCIÓN}

No resulta muy frecuente la valoración de los héroes y los próceres americanos por escritores españoles. Este desconocimiento de los valores americanos fue general durante prácticamente todo el siglo XIX abarcando escritores, poetas y científicos. Tal vez fuera un resultado lógico, emanado de los núcleos de poder españoles tras la independencia de las colonias, que afectó al ámbito cultural.

Fue, seguramente, Marcelino Menéndez Pelayo quien tuvo el mérito de haber sacado a la luz los valores literarios de algunos escritores americanos anteriores al siglo XX. Posteriormente, la figura de Rubén Darío se impuso por su propia fuerza, y en la Península no le escatimaron méritos ni le negaron su influencia en la renovación de la poesía española. Posteriormente, fueron Neruda, Mistral, Mutis, Úslar Pietri, Lezama Lima, García Márquez, Carlos Fuentes, etc. los que marcaron la línea creativa en la literatura en español. Por lo que respecta a las letras, pues, desde el Modernismo, el fenómeno del desconocimiento de la América Hispana, ya no existe o, en el mejor de los casos, ha sido reducido. Además, como muestran algunos trabajos $^{1}$, es un principio aceptado que el eje creativo e intelectual de la lengua española se movió hace ya mucho tiempo de España a Latinoamérica. Sin embargo, cuestión de distinta índole ha sido el reconocimiento de los héroes americanos, especialmente los de la Emancipación.

Uno de los escritores más reconocidos de las letras españolas, Unamuno, se liberó pron- to de prejuicios y resentimientos a propósito de Bolívar, al unificar en su figura distintos valores que el maestro de Salamanca admiraba especialmente: una gran conciencia cívica, patriotismo, y, sobre todo, una evidente capacidad intelectual. Miguel de Unamuno lo dijo claramente en una de sus citas más repetidas de «Don Quijote y Bolívar»:

«Ante todo, los hombres. Siempre me ha interesado más el individuo que la muchedumbre, las biografías más que las historias generales, y la psicología más que la sociología ${ }^{2} \gg$.

Bolívar unificaba al poeta y al héroe, ya que la figura diseñada por Unamuno del poeta representa la evolución que desde finales del siglo XIX transforma al escritor en intelectual, término popularizado a raíz del affaire Dreyfus ${ }^{3}$. Las siguientes palabras de Guillermo Carnero resumen la trascendencia de la mencionada evolución:

«Un escritor es el miembro de una categoría profesional que se dedica a la creación literaria. Un intelectual, además de un escritor, puede ser un cientifico en cualquier materia, por supuesto no necesariamente filológica, o un miembro de las profesiones liberales; pero, además, en el concepto mismo de «intelectual» está implícita una relación entre individuo pensante o creador, y sociedad, que presupone en el primero interés y actividad frente a las cuestiones públicas. El intelectual se siente miembro de un grupo internamente solidario y activo frente a la organización social, en la que desempeña un papel de fermento o de conciencia permanente, además de sentirse obligado a asumir, cuando sea necesario, conductas más decisivas ${ }^{4}$.
1

Carmen Alemany, La polémica del meridiano intelectual de Hispanoamérica (1927), Alicante, Universidad de Alicante, 1998.

2

M. de Unamuno, «Don Quijote y Bolivary en Obras selectas (ed. Julián Marías) Plenitud, Madrid, 1946, p. 1167.

3

L. Álvarez Castro, La expresión agónica, Universidad de Valladolid, Valladolid, 2001, p. 462.

4

G. Carnero, «El concepto de responsabilidad social del escritor en Miguel de Unamuno», Anales de literatura española, 1, Universidad de Alicante, Alicante, 1982 , p. 304.

Unamuno y Bolívar: invención de un pasado

FRANCISCO VILLENA GARRIDO 


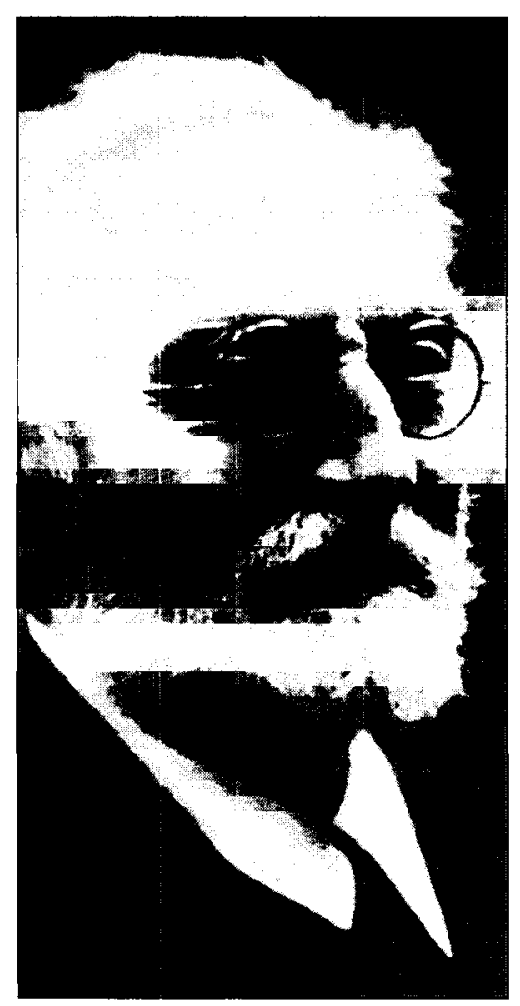

Miguel de Unamuno.

5

Según afirma Manuel García Blanco en América y Unamuno, "Don Quijote y Bolivar» apareció por primera vez en el diario argentino La Nación, el 30-11901, siendo su ensayo de la Historia constitucional de Venezuela (de Gil Fortoul) publicada en 1911, una reformulación de aquel artículo.

6

Libro en el que vuelve a reutilizar su artículo original de La Nación, en este caso como introducción.

Unamuno y Bolivar: invención de un pasado

FRANCISCO VILLENA GARRIDO
Simón Bolívar unificaba todas estas características: era un creador, un intelectual, un personaje implicado socialmente. Sin embargo, en realidad, no solía ser ésta la tónica habitual. Por eso, Unamuno dijo preferir la historia a la novela, y los hombres de acción a los contemplativos - a pesar de que en sus novelas parezca lo contrario: Abel Sánchez, Niebla, San Manuel Bueno, mártir, etc. y en gran parte de la producción de lo que Azorín llamó Generación del 98. No es de extrañar, pues, que entre sus figuras $\mathrm{fa}$ voritas encontremos a Bolívar, José Martí, Sarmiento, Zorrilla de San Martín, Joao de Deus, Antero de Quental, Vicente W. Querol, Carlyle, Wordsworth y Carducci, entre otros, aunque se mezclen varios criterios.

Respecto a sus trabajos de crítica literaria, destaca que únicamente se encargue de literatura hispanoamericana, como Valera, por razones prácticas, en realidad, fundamentadas en el deseo de no enemistarse con ningún contemporáneo español. Sin embargo, también resulta interesante ver esta apuesta como voluntad de expandirse al territorio hispano, como marco común de producción literaria. A pesar de todas sus excelencias, Unamuno era, en realidad, todo lo contrario a un crítico literario. Se cegaba en ocasiones, intentando convertir las diferencias en identidades, más allá de toda posible dialéctica.

Cuando nadie lo había dicho antes tan alto y tan claro, Unamuno publicó dos trabajos principales: el artículo «Don Quijote y Bolívar ${ }^{5} »$ y el libro Simón Bolivar, libertador de la América del Sur, visto por los más grandes escritores americanos ${ }^{6}$. En ambos unió al caraqueño con el héroe de Cervantes, honor insigne si se considera que don Quijote era para él, un símbolo máximo de los valores de «la raza hispánica». También aparece de forma más anecdótica en libros como Vida de Don Quijote y Sancho, comparando la locura bolivaresca por la pérdida de María Teresa Rodríguez del Toro, con la locura del Quijote por un amor silencioso, avergonzado y tímido.
BOLÍVAR Y LA «RAZA HISPÁNICA»

El patriotismo panhispánico de Unamuno resulta un rasgo de su personalidad bastante conocido. Debido a que en lo político todas las colonias se habían independizado, al menos en lo lingüísitco y cultural, el maestro de Salamanca pretendía que hubiera una uniformidad. Para ello crea términos como el de «raza hispánica» e insiste en los puntos en común de todos los pueblos Latinoamericamos con respecto a España - a veces forzando excesivamente.

Mediante un típico discurso de apropiación, Unamuno adoptó la figura de Bolívar para la hispanidad, revistiéndolo de valores españoles y queriendo ver un único espíritu supranacional que abarcaría a todos los países hispanos. La explicación de esta diferencia de valoración entre Unamuno y otros intelectuales de la época reside en que para el vasco, el Libertador era «nuestro Bolívar», uno de los más grandes y más representativos genios hispánicos.

Unamuno nacionaliza a Bolívar en la hispanidad, como gloria de su tierra y de su raza. El error español antes de Unamuno -y tal vez después también- es no haber incorporado al caraqueño en su rico patrimonio humano. Unamuno se atrevió a hacerlo ya que, dijo, que poseía un alma que enriqueció el alma española, el alma eterna de la España inmortal, y de la Humanidad con ella.

La admiración que le causa Bolívar, le lleva a identificar a Bolívar con el hombre español, con un Quijote de la América Hispana libertada. Señalando al caraqueño como uno de los más grandes héroes en que ha encarnado el alma inmortal de la Hispania máxima, miembro espiritual sin el que la humanidad quedaría incompleta.

Al final del artículo «El Quijote y Bolívar", Unamuno vuelve a su recurrente idea de la gran Hispania, insistiendo en la necesidad de conocerse entre sí: «Porque no es sólo que en España se conozca poco y mal a la América latina, y que en ésta se conozca no mucho ni muy bien a España, sino que sospecho que las repúblicas hispanoamericanas, desde Méjico a la Argentina, se conocen muy superficialmente entre sí».

Unamuno sigue a Bolívar a través de su vi$\mathrm{da}$; lo ve en los días iniciales de la gesta eman- 
cipadora; lo sigue en la tierra natal y en el destierro; lo saluda triunfador o derrotado, lo juzga como conductor de masas o de ejércitos, como estadista o como general. Sin embargo, siempre lo ve como un héroe de la estirpe común, un hombre que heredó y es fiel a lo mejor de la raza hispana.

La apropiación de Bolívar para la tradición hispánica queda patente en las reflexiones de Unamuno. Incluso cuando trata la psicología del caraqueño, aprovecha para introducirlo en una misma tradición cultural. Señala el maestro de Salamanca:

«Hay una frase profunda, profundísima, tal vez la frase más profunda que he leído de Bolívar — con frecuencia hay en sus frases célebres más retórica a la española que no otra cosa-, hay una frase que nos hace penetrar hasta el hondón del alma del héroe. Es cuando, en 1824, escribía al marqués del Toro: «Entienda usted, mi querido marqués, que mis tristezas vienen de mi filosofía; y que yo no soy más filósofo en la prosperidad que en el infortunio. Esto lo digo para que usted no crea que mi estado es triste, y mucho menos mi formuna». ¿ No os dice nada esto del hombre triste en la prosperidad y triste por filosofía? ¿Llegaría Bolívar a sentir la angustia metafísica de todos los grandes, la terrible voz que surge del silencio de las eternas tinieblas, y nos dice: ¿y todo, para qué??».

Uno de los aspectos más importantes en la defensa de Bolívar por parte de Unamuno es negar de forma rotunda el supuesto antiespañolismo del Libertador. Asegura que cuando Bolívar habla del odio que separa América de la Península es pura retórica. Para probarlo asegura que basta recordar que Bolívar señaló en otra ocasión: «Es nuestra ambición ofrecer a los españoles una segunda patria, pero erguida, no abrumada de cadenas». En su larga campaña no dejó de aclarar que la guerra la hacía al Gobierno español no a su pueblo, y que no debía confundirse al Gobierno de España con los españoles.

\section{BOLÍVAR Y EL QUIJO'TE}

Acérquese usted, doctor. Se lo diré al oído. Los tres grandísimos majaderos hemos sido Jesucristo, Don Quijote y yo. (Simón Bolívar, diciembre 1830)

Las últimas palabras que la tradición ha asignado a Simón Bolívar resumen el senti- miento de un hombre humillado, hostigado, hundido por las ambiciones personales de quienes lo acompañaron en su aventura emancipadora. El crimen Berruecos, La conjura de La Cosiata, la dictadura que se vio obligado a ejercer, sus sucesivas huidas, las ambiciones de Páez y de Santander lo llevan pronunciar aquel desesperado "he arado en el mar».

La historia de los pueblos que libertó no ha variado sustancialmente: su Gran Colombia, cual Ínsula, sigue siendo una utopía; sus palabras se han convertido tan sólo en adornos utilizados en los discursos proselitistas de políticos y mandatarios de turno; los ejércitos son una horda usada por el poder, contra el pueblo, que abona la tierra de la opresión.

La vida de Simón Bolívar, según Unamuno, es pródiga en muestras de quijotismos -al margen de su gusto por los libros de caballerías. La tradición literaria literaria ha recogido tres ejemplos. El primero de ellos se sitúa en el Viernes Santo de 1812, cuando un tremendo terremoto castiga a Caracas; un fraile ocupa una tribuna y lo atribuye al azote de dios por haberse desconocido a Fernando VII. El futuro Libertador sube a la mesa que servía de improvisado púlpito al fraile y pronuncia sus inmortales palabras: «Si se opone la Naturale$\mathrm{za}$, lucharemos contra ella y haremos que nos obedezca». El segundo, cuando propone en Panamá a Pedro Gual organizar una expedición libertadora de Cuba y Puerto Rico, y que con mayores fuerzas marcharía después a España si para entonces no se conociera la paz: «Acaso - anota Unamuno- se habrían resuelto no pocas cosas si nos hubiera conquistado Bolívar, digo a nuestros abuelos ${ }^{8}$. El tercer ejemplo, citado en varios trabajos unamunianos, trata de los últimos días en los que preguntó a su médico si sabía quiénes habían sido los tres más insignes majaderos del mundo, y al decirle el interpelado que no, le contestó: «Los tres grandísimos majaderos hemos sido Jesucristo, Don Quijote y yo».

Es evidente que hay algo quijotesco en un Bolívar obsesionado en crear una enorme nación, una especie de Ínsula, tratando de hacer coincidir los ideales que ha sacado de libros con la realidad -a pesar de que todo ello fuera fruto consciente de una educación plenamente europea.
7 Op. cit. (2), p. 1171. 8 Op. cit. (2), p. 1172.
Unamuno y Bolívar: invención de un pasado

FRANCISCO VILLENA GARRIDO 


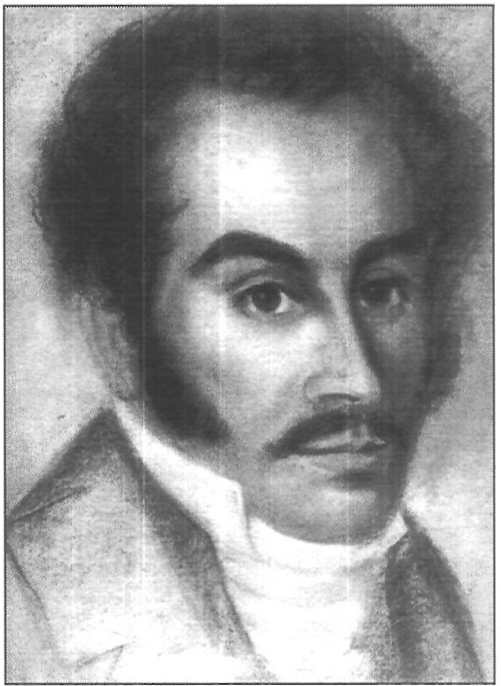

Retrato de Simón Bolívar.

9

J.C. Chaves, Unamuno y América, Cultura Hispánica, Madrid, 1964, p. 73.

10

Op. cit. (2) 1170.

11

R. Blanco Fombona, "Bolivar Escritor» en Miguel de Unamuno, Simón Bolivar Libertador, Buenos Aires, Editorial Las Novedades, Tomo II, 1944, pp. 35-36.

\section{2}

S. Bolivar, Manifiesto de Carra gena, Biblioteca Virtual Miguel de Cervantes, Universidad de Alicante, 2000. Edición digital a partir de Docirina del Libertador, $3^{a}$ ed., Caracas, Biblioteca Ayacucho, 1985, pp. 8-17.

Unamuno y Bolívar: invención de un pasado

FRANCISCO VILLENA GARRIDO
Como en la segunda parte de $E l$ Quijote, Bolívar se encuentra con obras literarias donde él mismo aparece. Hay varios ejemplos, como el libro sobre la vida galante de Lima que Manuela le lee; $O$ en una de las paradas del viaje final, cuando una niña le recita al General estrofas de la oda de Olmedo, «La victoria de Junín: Canto a Bolívar», poema que compuso asesorado por el mismo Libertador. Sin embargo, el elemento cervantino se aprecia, principalmente, en el cariz revivificador del viaje de Bolívar, ya que como don Quijote en su último regreso al hogar, vuelve a vivir experiencias de su trecho de aventuras, y se encuentra, de alguna manera, con los personajes que desempeñaron algún papel, y que surgen para redondear la historia del caraqueño.

Pese a resultar paradójico, parece que Bolívar ya estuviese leyendo su propia vida antes de morir, como si este arduo final de la vida del Libertador fuese básicamente un final que constituyese a su vez un comienzo de la propia lectura.

Otros muchos ejemplos de quijotismo se pueden hallar en la vida del Libertador?. Quijotismo y de especial relevancia es el «Delirio sobre el Chimborrazo»: "Yo venía con el mando de Iris, donde paga su tributo el caudaloso Orinoco al dios de las aguas. Había visitado las encantadas fuentes amazónicas y quise subir al Atalaya del Universo (...) Llego como impulsado por el genio que me animaba y desfalleciendo al tocar con mi cabeza la copa del firmamento: tenía a mis pies los umbrales del abismo. Un delirio febril embarga mi mente; me siento como encendido por un fuego extraño y superior. Era el dios de Colombia que me poseía».

La muerte de Bolívar tiene los mismo resplandores del ocaso del noble manchego. «Por más triste que sea nuestra muerte - escribió- siempre será más alegre que nuestra vida». Don Quijote y Bolívar se parecen no sólo en sus vidas sino también en sus muertes. «Los últimos momentos del gran Libertador - anota Unamuno- son de tan intensa poesía como los últimos momentos del caballero manchego $0^{10}$ ».

\section{BOLÍVAR COMO ESCRITOR}

La valía literaria y creadora de Simón Bolívar parece evidente con la simple lectura de sus escritos. La capacidad en la escritura se muestra de forma majestuosa en sus cartas -concisas y bellas-, sus proclamas - repletas de poesía épica-, sus discursos persuasivos - dignos de la época clásica-, y sus documentos. Toda esta producción escrita se encuentra repleta de una armonía admirable entre la sobriedad del estilo y la altitud conceptual.

Cuando Simón Bolívar se muestra como pensador, como en el Congreso de Angostura, la expresión gana en profundidad lo que pierde en brillo. Había una evidente voluntad de estilo en la producción bolivariana, pero la temática y el apasionamiento distorsionaban, en ocasiones, esta voluntad. La concisión nunca fue una de las virtudes de la escritura del caraqueño. Como señala Blanco Fombona ${ }^{11}$, «lo que faltó siempre en su estilo y en su vida fue la serenidad, la placidez, la calma». El Manifiesto de Cartagena evidencia las características de este tipo de escritos:

«Conciudadanos. Libertar a la nueva Granada de la suerte de Venezuela y redimir a esta de la que padece, son los objetos que me he propuesto en esta memoria. Dignaos, oh mis conciudadanos, de aceptarla con indulgencia en obsequio de miras tan laudables. Yo soy, granadinos, un hijo de la infeliz Caracas, escapado prodigiosamente de en medio de sus ruinas físicas y políticas, que siempre fiel al sistema liberal y justo que proclamó mi patria, he venido a seguir los estandartes de la independencia, que tan gloriosamente tremolan en estos Estados.

Permitidme que animado de un celo patriótico me atreva a dirigirme a vosotros, para indicaros ligeramente las causas que condujeron a Venezuela a su destrucción, lisonjeándome que las terribles y ejemplares lecciones que ha dado aquella extinguida República, persuadan a la América a mejorar su conducta, corrigiendo los vicios de unidad, solidez y energía que se notan en sus gobiernos ${ }^{12}$.

Es en sus cartas donde mejor se muestra Bolívar, según Unamuno, porque es en este registro donde se muestra más cercano, libre para expresar sus pensamientos y sentimientos.

«Dotado de una imaginación ardiente de poeta de la acción, potente idealista, en sus cartas es donde el Li- 
bertador, al revés de la mayor parte de los héroes, nos parece más admirable y, desde luego, más amable (...) Por ellas sentimos correr el escalofrío de una grande alma emotiva, vibrante; conocemos las sensaciones de aquel temperamento; vemos cálidos torrentes donde se confunden efusiones de amistad, planes de guerra, meditaciones de república ${ }^{13}$ ».

La Carta de Jamaica es, sin duda, uno de los grandes logros creativos y de síntesis política de Bolívar:

«Cuando los sucesos no están asegurados, cuando el estado es débil y cuando las empresas son remotas, todos los hombres vacilan, las opiniones se dividen, las pasiones las agitan y los enemigos las animan para triunfar por este fácil medio. Luego que seamos fuertes, bajo los auspicios de una nación liberal que nos preste su protección, se nos verá de acuerdo cultivar las virtudes y los talentos que conducen a la gloria; entonces seguiremos la marcha majestuosa hacia las grandes prosperidades a que esta destinada la América meridional; entonces las ciencias y las artes que nacieron en el Oriente y han ilustrado la Europa volarán a Colombia libre, que las convidara con un asilo ${ }^{14}$.

\section{BOLÍVAR COMO PERSONAJE LITE- RARIO}

Unamuno nunca introdujo a Simón Bolívar en su creación literaria, sino que, únicamente, fue objeto de análisis y encomio en sus ensayos y artículos. Sin embargo, el caraqueño ha sido un personaje recurrente en gran parte de la producción artística de Latinoamérica desde su muerte e incluso antes.

El personaje se retomó de muchas formas diversas, aunque prácticamente siempre con la poeticidad que el personaje sugiere: todo lo que había luchado por conseguir estaba desapareciendo ante sus ojos. $\mathrm{Y}$ al final de sus días se compara a sí mismo con su antiguo favorito, don Quijote, un loco que había hecho el ridículo tratando de enderezar los entuertos del mundo.

En el siglo XX se rescató la figura de Bolivar de forma recurrente. Sin embargo, no fue como personaje monolítico, marmóreo, dechado de virtudes. La modernidad y, sobre todo, la posmodernidad ha dotado al Libertador de una personalidad compleja como prueban obras de radical importancia como las de Álvaro Mutis, El último rostro, y Gabriel García Márquez, El general en su laberinto.

\section{A MODO DE CONCLUSIÓN}

Bolívar es unamunesco por excelencia. Por su físico, su espíritu, su vida su obra, parece un personaje de la novela que Miguel de Unamuno no escribió sobre la Independencia.

Las pinceladas que Unamuno hace de Bolívar no constituyen un retrato de cuerpo o alma completos, pero tienen atisbos profundos, sorprendentes, geniales, si se tiene en cuenta que el material y la bibliografía que dispuso no fue muy rico. No tuvo a manos ni la colección de cartas ni las obras completas, pero supo darnos un Bolívar grande.

De Bolivar a Unamuno le interesa la conjunción perfecta entre hombre de acción, intelectual y poeta, hombre volcado en la sociedad con profundas motivaciones éticas. De ahí su apasionamiento voraz, su interés en apropiarse de su figura para la hispanidad, como estandarte de la panhispanidad, en negación del antiespañolismo que, en ocasiones, se ha señalado.

La figura de Simón Bolívar supera la coyuntura histórica para convertirse en un personaje capital en la Emancipación y en la historia de Latinoamérica. Podemos apreciar su imagen en las letras hispanas desde el siglo XIX hasta nuestros días. La historia lo ha juzgado de una manera diferente de cómo lo hicieron sus contemporáneos: un hombre con una percepción más profunda de su circunstancia histórica, un visionario que entendió las necesidades de su país, y un hombre de acción que actuó con decisión para satisfacerlas.

\section{BIBLIOGRAFÍA}

AA.VV., Anales de literatura española, 1, Universidad de Alicante, Alicante, 1982.

ALEMANY, C., La polémica del meridiano intelectual de Hispanoamérica (1927), Universidad de Alicante, Alicante, 1998.

ALTUVE CARRILLO, L., Don Quijote Bolivar, Secretaría General de la Comisión Nacional para la Conmemoración del Quinto Centenario del Descubrimiento de América, Santafé de Bogotá, 1993.

ÁLVAREZ CASTRO, L., La expresión agónica, Universidad de Valladolid, Valladolid, 2001.

\section{3}

M. de Unamuno, Op. cit. (11) pp. 209-213.

14

S. Bolivar, Carta de Jamaica, Biblioteca Virtual Miguel de Cervantes, Universidad de Alicante, Alicante, 2000. Edición digital a partir de Doctrina del Libertador, $3^{a}$ ed., Caracas, Biblioteca Ayacucho, 1985, pp. 55-75.
Unamuno y Bolívar: invención de un pasado

$\overline{\text { FRANCISCO VILLENA GARRIDO }}$ 
BOLÍVAR, S., Carta de Jamaica, Biblioteca Virtual Miguel de Cervantes, Universidad de Alicante, Alicante, 2000. Edición digital a partir de Doctrina del Libertador, $3^{\mathrm{a}}$ ed., Caracas, Biblioteca Ayacucho, 1985.

BOLÍVAR, S., Manifiesto de Cartagena, Biblioteca Virtual Miguel de Cervantes, Universidad de Alicante, 2000. Edición digital a partir de Doctrina del Libertador, $3^{\mathbf{a}}$ ed., Caracas, Biblioteca Ayacucho, 1985.

CHAVES, J.C., Unamuno y América, Cultura Hispánica, Madrid, 1964.
GARCÍA BLANCO, M., América y Unamuno, Gredos, Madrid, 1964.

REINATO, E.J., El Quijote de los Andes: Bolivar e o imaginário da Independência na América-1810-1830, Universidad Católica de Goiás, 2001.

UNAMUNO, M. de, Obras selectas (ed. Julián Marías) Plenitud, Madrid, 1946.

UNAMUNO, M. De, Simón Bolivar, libertador de la America del Sur, por los más grandes escritores americanos, Renacimiento, Madrid, 1914. 